\title{
The Effect of Road Infrastructure on Traffic Accidents
}

\author{
Ardilson Pembuain, Sigit Priyanto, and Latif B. Suparma
}

\begin{abstract}
Planning, Designing and constructing road infrastructure should give priority to the safety and comfort for road users. Ironically, road infrastructure often becomes the cause of traffic accidents. However, such problem can be solved with a profound understanding in the effect of road infrastructure formation elements on the risk of accidents, so that the handling taken can be more efficient. This study aims to (1) review and see the effect of road infrastructure on accidents, (2) provide handling efforts to improve road infrastructure safety. Secondary sources in the form of books and academic journals were reviewed to answer the research objectives above. The results of the study indicated that the elements in road infrastructure formation had significant effect on the risk of traffic accident. Preventing and handling traffic accidents in terms of the road infrastructure can start from planning, designing, constructing, and improving road infrastructure in accordance with prevailing procedures such as Road Safety Audit (RSA) and Road Safety Inspection (RSI). The role of government such as making safety design standard, assuring compliance with these rules, and methods to measure and rate the overall level of safety being achieved is needed in order to improve road safety.
\end{abstract}

Index Terms-Safety, road infrastructure, road infrastructure elements, traffic accidents, road users.

\section{INTRODUCTION}

$\mathrm{T}$ raffic safety is one of the global issues that have to be taken seriously. The World Health Organization (WHO) in 2015 [1] shows that the number of traffic accidents occurring around the world did not decrease, but increases from 2001 to 2013. WHO also shows that traffic accidents have killed more than 1.2 million people annually and become the number one cause of death among those aged 15-29. Several literatures show that human, vehicles, roads and environment, as well as interaction between these factors are the main causes of traffic accidents. Road infrastructures as one of the causes of traffic accident should be designed and constructed by accommodate all aspects of safety for its users

A. Pembuain is with the Student, Doctoral Program of Civil and Environmental Engineering, Faculty of Engineering, University of Gadjah Mada, 55281, Yogyakarta, Indonesia (e-mail: ardilson_pembuain@yahoo.com).

S. Priyanto is with the Civil and Environmental Engineering Department, Faculty of Engineering, University of Gadjah Mada, 55281, Yogyakarta, Indonesia.

L. B. Suparma is with the Civil and Environmental Engineering Department, Faculty of Engineering, University of Gadjah Mada, 55281, Yogyakarta, Indonesia. into consideration in order to minimize the risk of traffic accidents.

Road width that is too narrow or doesn't comply with standards, sharp curves, steep downhill and uphill, pavement surface damage, and non-illuminated roads are some of the factors that cause traffic accidents. Road infrastructure that should provide the users safety and comfort, ironically becomes the cause of traffic accidents. Therefore, a profound study to reduce traffic accident due to road infrastructure and to understand the influence of each element that form road infrastructure on traffic accidents should be performed so that the process of handling road safety can be more effective.

The objectives of this research are to (1) see and discuss the effect of road infrastructure on traffic accidents and (2) provide handling efforts to improve road infrastructure safety. This study employed secondary sources in the form of academic journals and books relevant to this study, which were review and discussed to answer both research objectives above. This research was not limited to certain types of roads. In this study, the effect of road infrastructure on traffic accidents was seen and discussed in general. Furthermore, it is expected this research to provide more profound knowledge and understanding of the importance of providing a well designed and constructed road infrastructure by taking the safety aspects into consideration so as to minimize the risk of traffic accidents.

In general, the discussion in this study is divided into 3 main sections. First, research method describes the methods and data employed as well as also general description of the analysis process. Second, analysis and discussion to explore the influence of road infrastructure on traffic accidents and explains some efforts to improve the safety of road users. Third, the conclusion is the results of the discussion and analysis of the previous sections.

\section{RESEARCH METHODS}

The two main issues that want to be answered in this study are discussing the influence of road infrastructure on traffic accidents and showing the efforts that can be done to improve traffic safety. Article review was used to answer both research objectives in which secondary sources in the form of academic journals and books relevant to this study were collected, reviewed and discussed in order to answer both research questions above. The analysis and discussion process in this study were divided into 3 main sections:

- Breaking down the road infrastructure into its elements. 
- Discussion to explore the influence of road infrastructure elements on traffic accidents

- Discussing efforts that should be made to improve safety in terms of road infrastructure.

\section{ANALYSIS AND DISCUSSION}

\section{A. Elements of road infrastructure}

Before discussing the effect of road infrastructure on traffic accidents, road infrastructure should be broken down into its constituent elements. The division of road infrastructure into its constituent elements would make the discussion easier because it would focus on the influence of each element on the risk of accidents. The road infrastructure elements were determined based on the following premises:

- Road infrastructure is defined as a land transport infrastructure including all parts of the road, including complementary buildings and equipment intended for traffic [2].

- In order to build a secure road infrastructure, roads must be built on the principles of security and safety. Security related to requirement of road engineering and safety concern with road surface conditions and geometric conditions [2].

- Roads that are feasible to operate should technically comply with: (a) road geometry; (b) pavement structures; (c) road complementary building structure; (d) use of parts of the road; (e) traffic management and engineering; and (f) road equipment [3].

Based on the three premises above, this research divides the elements of road infrastructure as follows: (a) Geometric (lane width, horizontal curves, and vertical curves), (b) Road surface condition, (c) Road side hazard, (d) Complementary building of the road (sidewalk and bus bays), and (e) Road equipment (markings, signs, and lights). The five elements and sub elements will be discussed to see the effect on traffic accidents in the next section.

\section{B. Influence of road infrastructure elements on traffic accidents}

Table I show the literature used to discuss the relationship between elements of road infrastructure and traffic accidents. Discussion of the influence of each element in causing the accident will be explained later.

TABLE I

LITERATURE

\begin{tabular}{llc}
\hline \hline \multicolumn{1}{c}{ Element Of Road } & \multicolumn{1}{c}{$\begin{array}{c}\text { Sub Elements of Road } \\
\text { Infrastructure }\end{array}$} & Literature \\
\hline Road Geometric & Lane width & \\
& Horizontal curve & {$[4]-[11]$} \\
& Vertical curve & {$[12]-[16]$} \\
Road Surface & & {$[15],[17]-[20]$} \\
Conditions & & {$[21]-[28]$} \\
Roadside Hazard & & \\
Road Complementary & Sidewalk & {$[29]-[38]$} \\
Building & & {$[39]-[45]$} \\
& Bus bay & \\
Road Equipment & Marking & {$[46]-[51]$} \\
& Signs & {$[52]-[58]$} \\
& & {$[59]-[63]$}
\end{tabular}

Lights [64]-[69]

\section{1) Road Geometric}

Lane Width - Each type of road has a range of width requirements for the lane in its design. For example, on highway design policies for arterial roadways indicating that the range of usable widths is $3.0 \mathrm{~m}$ to 3.6 meters [4]. This width is also applicable for other types of roads with variations of different lane width ranges. The flexibility of determining the width of the given lane is based on environmental and economic conditions.

Related to the lower limits and upper limits of the width of the lane, there is a conventional wisdom that says: the narrower the lane, the higher traffic accident rate [5]. This is because the wider the lane, the wider the distance between vehicles moving between the adjacent lanes thus providing a larger space for improving position when the accident almost takes place [6].

Research conducted by Potts et al. [5] aiming to prove such revelation on urban and suburban roads suggest that the use of lane widths smaller than $3.6 \mathrm{~m}$ does not indicate an increase in the number of accidents on urban and suburban roads. This research suggests that geometric design procedures should provide flexibility for narrower lanes.

This is in contrast to research conducted by Hadi \& Aruldhas [7] which suggests that wider urban road lanes are safer for the four-lane urban undivided $(3.7 \mathrm{~m})$ and six lane urban freeways $(3.7 \mathrm{~m})$. This is consistent with other studies [8]-[11] which suggest that roads with wider lanes can reduce the rate of traffic accidents.

In general, the studies described above show the effect of the width of the lane on traffic accidents as well as the lane width range requirements for each type of road. The use of the upper limit of the road width is preferred to guarantee the safety of road users.

Horizontal Curve - Horizontal curve is a section or segment of the road that provides a transition from one straight road to the next straight road. Drivers will experience a centrifugal force as they pass through the horizontal curve segment which makes the driver must react to this force in order to pass the segment safely so that an accident will not take place [12]. In their research, Hall \& Hall [12] showed that the number of traffic accidents in the horizontal segment from 2003 to 2005 in North Carolina was 95,552 incidents for all types of roads. Banihashemi [13] also added that the effect of horizontal curve on accidents is significant in the type of two lane undivided urban arterials. In addition, the most common types of accidents in the horizontal curve area are run off road crushes and head on crashes [14].

Several attempts have been made to understand the effect of horizontal curve characteristics on traffic accidents, and the results found indicate that the geometric characteristics of the horizontal curve that affect the occurrence of accidents are radius, length, presence of adjacent curves, the presence of transition curves and super elevation [15], [16].

Some efforts that can be made to improve the safety of road users related to geometric problems is performing good 
geometric planning and design, improving harmful geometric on the existing road, providing advanced warning in horizontal curves and combining it with road marking.

Vertical Curve - Vertical curves are used to provide a smooth transition between vertical tangents of different grade. It is parabolic curve and is usually centered on the intersection point of the vertical tangents [17]. In general, vertical curves are divided into two: crash curves and sag curves [15]. In relation to the issue of traffic accidents, several studies have shown statistically that vertical curve is one of the causes of accidents.

Research conducted to understand the correlation between vertical curves and traffic accidents indicate that the geometric characteristics of vertical curves such as steep gradient and continuous long descent are very influential on the occurrence of accidents [18]. This may be due to vehicles with very different climbing capabilities running together on slopes with high steepness can affect the level of road capacity and the risk of traffic accidents. In addition, the rate of traffic accidents in the vertical curvature of the downhill direction is higher than that of the uphill direction [19]. This may be due to the continuous downhill segment of the brake burning out or losing effectiveness, so the length of longitudinal must be limited.

Sharp crest and sag curves can affect traffic accidents in the same way as horizontal curves because of the short visibility of the crest curves and the far reaching distance of the sag curves can increase the risk of accidents [15]. In addition to the above factors, one of the vertical curved geometric characteristics affecting road safety is the width of the road [20].

Thus, it can be said that the planning and design of vertical road curves that are not steep and long should be avoided in order to improve the safety of road users passing through such vertical curve segment.

\section{2) Road Surface Conditions}

Road surface or pavement distress is a condition of road damage such as cracking, patching and potholes, surface deformation, and surface deflect [21]. This research discusses the effect of pavement distress on the risk of accidents based on collective damage conditions of pavement surfaces. Road surface condition is a matter of concern especially for traffic safety aspect. Poor road surface conditions (large potholes and deep crack exists, discomfort at slow speeds) can lead to high rate of accidental fatality, especially in high speed roads in single vehicle and multi vehicle accident types [22].

Several studies [23]-[28] have been conducted to see the relationship between traffic accident and road surface conditions. In general, the results of these studies indicate that there is a close correlation between road surface conditions and the frequency of traffic accidents. The recommendations given by Chan et al [27] and $\mathrm{Li}$ et al [26] are a good maintenance process on pavement surface conditions can reduce the rate of traffic accidents. Furthermore, road should be maintained under acceptable conditions above poor to keep the safety and comfort of road users [22].

\section{3) Road Side Hazard}

A roadside Hazard is any fixed object located on the side of the road within a free area that can increase the severity of the crash [29]. In general, these road side hazards are miscellaneous fixed objects, sign supports, tree groups, and utility poles along the roadway [30]. This dangerous roadside condition is very influential on the severity of run-off type road accident (ROR) [31, 34] because when the vehicle undergoes run off road accident, the driver who cannot control the vehicle is at risk of hitting trees or dangerous objects in side of the road that can increase the level of accidental fatalities.

In addition to some of the above studies, researches to see the effect of roadside hazards on the fatality rate of casualty victims have been done since a long time ago. In general, these studies conclude that roadside hazard conditions such as trees and others can aggravate the fatalities of traffic accidents $[35,38]$.

Some of the recommended measures for dealing with this problem are eliminating hazards, relocating hazard, modifying hazard, closing hazard, or using the concept of clear zone where road side can be driven and clean from hazard object [29].

\section{4) Road Complementary Building}

Sidewalk - Traffic activities are generally reserved for vehicular traffic and pedestrian traffic [39]. It is important to take pedestrian safety into consideration because the traffic process begins and ends by walking. One of the facilities of pedestrian infrastructure is sidewalk. In regard to pedestrian safety issues, sidewalks that no longer work well because of damage such as deterioration, pitting, spilling, scaling, cracking, and heaving make pedestrians difficult to use such facilities [40], in addition, blocked sidewalk can also make pedestrians enter the road body which may harm themselves and other road users [41].

Studies related to sidewalk functionality for the safety of road users have been undertaken by some earlier researchers and, in general, those studies demonstrate well-designed [42, 43] and well maintained pedestrian facilities [40, 44, 45] so that pedestrians can use the sidewalk facility in accordance with its function that will improve the safety of every road users.

Bus bay - The bus stop is part of an important complementary road building in a transportation system. The bus stop serves to load and unload passengers [46]. Generally, the bus stop is divided into two: Curb side bus stop and bus bay $[46,47]$. In relation to traffic safety, bus stops can affect the high risk of accidents [48], especially for buses that are not separated by their own lane.

Several studies have been conducted to see how the impact of these two bus stop types on accidents. Curb bus stops can cause long bottlenecks and delays due to large bus dimensions $[46,49]$, in addition, curb stops that are parallel to roads will cause large traffic conflicts due to vehicle maneuvering behind buses as well as buses pulling in and out [47]. Some of these things cause the bus stop is very risky to traffic accidents.

Unlike the bus stop, the bus bay can disentangle the flow of 
the vehicle better [50,51], in addition, the number of conflict between bus and other vehicles on the mixed traffic is fewer so it is safer than the curb bus stop [47]. Some of these studies suggest that the use of bus bays would be better for areas with high traffic volumes than bus curb in terms of road safety.

5) Road Equipment

Marking - Marking is defined as a sign on the surface of the road or on the road surface that includes equipment or signs that form longitudinal lines, transverse lines, slanting lines, and symbols that serve to direct the flow of traffic and limit the area of the traffic [52]. In terms of the function of road markings, it can be said that marking plays a significant role to maintain the safety of road users, especially when the visibility becomes the main factor.

One of the environmental influences on traffic accidents is driving at night or in bad weather which results in a decrease in driver's visibility [53]. When visibility is bad, good road marking conditions can improve road users' safety [54, 57]. In addition, other studies have also shown that the use of edge lines in curve can improve the safety of road users [58].

Generally speaking, the conclusions drawn from these studies indicate that road markings can help drivers feel more comfortable and help drivers look at their lanes when passing through areas with low visibility (night or rain).

Signs - Traffic signs are part of street equipment in the form of symbols, letters, numbers, sentences, and/or combinations that serve as warnings, prohibitions, orders or directions for road users [59]. Like road markings, the functions of signs are critical to the safety of road users as they can provide warnings or clues to road conditions.

The effect of signs on traffic safety such as variable messages can affect driver behavior to decrease vehicle speed [60]. The use of road signs can also improve safety in the curve segment. The use of warning signs and speed limits may decrease the speed of vehicle users as it approaches road curves [61]. This is supported by other studies showing that the use of chevron signals has a significant effect on the decrease in velocity in curved areas [62] and the addition of herring bones, chevron markers, and repeater arrow signs can decrease and maintain vehicle position in the lane in the curved segment [63].

Lights - In general, lights work to illuminate the street environment at night. One of the road environmental factors that affect the occurrence of accidents is night at which visibility becomes a major problem [64]. The risk of accidents occurring with high severity is more prevalent at night [65]. One of the efforts that can be made to reduce the number of traffic accidents at night is by using street lighting.

The effect of street lighting on traffic accidents has been done by several researchers and they show that the number of traffic accidents on roads without lights is higher than roads without street lighting, either on straight road segments [66, 67], curved road [67] as well as on the intersection segment $[68,69]$.

\section{Efforts to handle traffic accidents in terms of road infrastructure}

Discussions about the influence of road infrastructure elements on the risk of accidents show that the road infrastructure has very significant effect on traffic accidents. The results are reinforced by the WHO in 2015 [1] in a report entitled Global Status Report of Road Safety indicating that the improvement of road infrastructure is a key mechanism for the making of safer roads.

The life cycle of road infrastructure is planning, design, build, operate, decommission [70]. Road infrastructure safety conditions should be handled at each stage of the cycle in order to maintain road users' safety and comfort. Road Infrastructure Safety Management (RISM) is one of the road safety management efforts in terms of the road infrastructure $[70,72]$. RSIM is a set of procedures that support decisionmaking by relevant road authorities to improve the safety of road infrastructure networks that can be implemented at an early stage of the project life cycle that allows a proactive approach on roads to be built as well as on existing roads that allow a reactive approach [72]. In general, RSIM has many tools that can be applied to improve the safety of road infrastructure. However, the most commonly used tool is Road Safety Audit (proactive) that begins in the planning, design, construction, and pre-opening and Road Safety Inspection (reactive) stages applied to existing roads for maintenance or renewal processes [70, 72]. Jamroz et al [70] also said that Road Safety Audit can reduce 10-25\% of casualties while road safety audit is $1-20 \%$.

Not enough just by doing the above efforts to improve traffic safety. Bener et. al [73] in his research titled Strategy to Improve Road Safety in Developing Countries said that the difference between developed and developing countries is in the way reducing the number of accidents because road safety is more appreciated in developed countries and there is no way to improve safety roads but adopting comprehensive preventive and handling strategies for the prevention of traffic accidents and this can be done through close collaboration between traffic police, health, law, and transport authorities. Such results are consistent with the WHO's 2015 Decade of Action (DoA) program [1]. The importance of government factors in reducing the level of traffic accidents is shown in fig. 1. Bliss et al [74] discussed about the new road safety management tools that have been developed by World Bank and ISO as shown in fig. 1 which can be used as road safety work framework. In general, road safety management is production process with three interrelated elements i.e. institutional management functions produce interventions that produce results. This means that the seriousness and commitment of the government in improving traffic safety is a key factor in handling traffic accidents. The government's direct role for road infrastructure safety, which is by making safety design standard, assuring compliance with these rules, and methods to measure and rate the overall level of safety being achieved. 


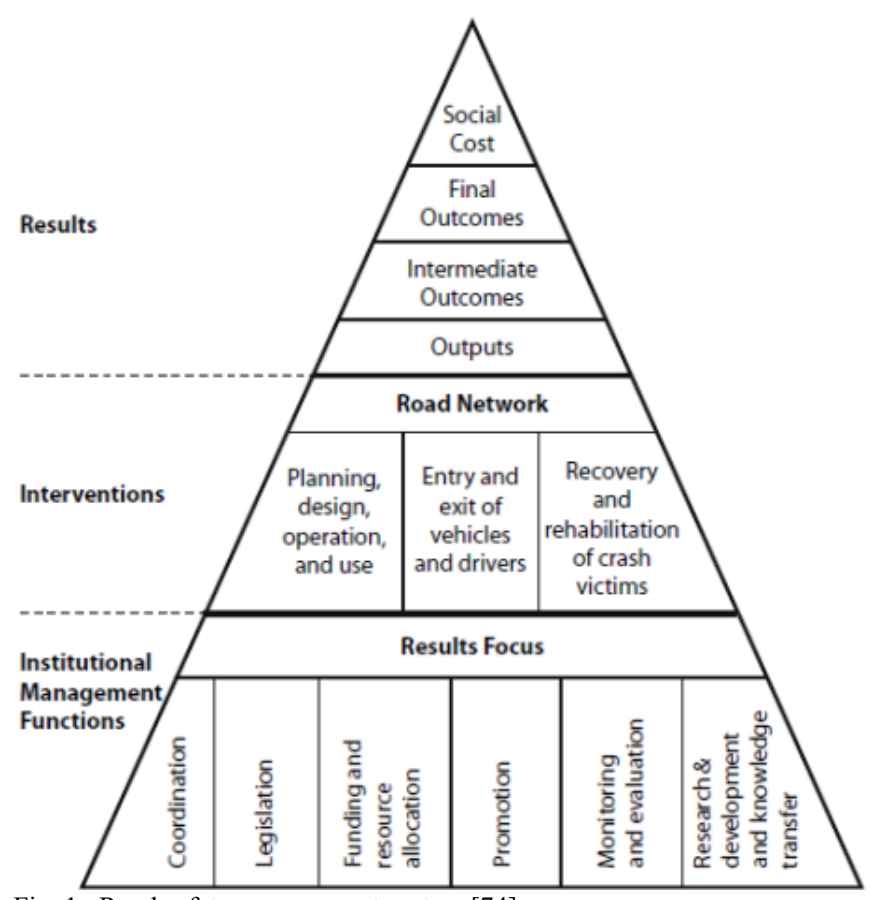

Fig. 1. Road safety management system [74]

\section{CONCLUSIONS}

This study aims to (1) review and see the impact of road infrastructure on accidents, (2) provide handling efforts to improve road infrastructure safety. There are three conclusions that can be drawn, namely:

a. In order to see the effect of road infrastructure on traffic accidents, this study divided road infrastructure into its constituent elements and then observed the correlation between each element of the road infrastructure and the accidents they caused. The results of this study indicated that road elements such as road geometry, road surface conditions, road side hazards, road complementary buildings, and road equipment have significant effect on traffic accidents. Therefore, a safe road infrastructure is a road infrastructure in which each element is built according to the planning standards by taking all aspects of safety into consideration.

b. The life cycle of road infrastructure is plan, design, build, and operate. Implementation safe road infrastructure must begin at each stage of the life cycle of road. This can be done by using some RISM tools such as Road Safety Audit (RSA) conducted at the planning, design, construction and early stage of road operation and Road Safety Inspection (RSI) conducted on existing road. The use of these two tools has been proven to reduce the rate of traffic accidents by $10-25 \%$ and $1-20 \%$ respectively.

c. The seriousness and commitment of the government are key factors in the handling of traffic safety. Government efforts such as making a standard safety design, assuring compliance with these rules, and methods to measure and rate the overall level of safety being achieved will help improve traffic safety from the aspect of road infrastructure. However, these efforts are not sufficient. A comprehensive traffic accidents handling strategy and close collaboration between traffic police, health, law, and transport authorities in preventing and resolving traffic accidents can increase the traffic safety level of a country.

\section{REFERENCES}

[1] World Health Organization, "Global Status Report on Road Safety," 2015.

[2] Undang-Undang Republik Indonesia Tentang Jalan, Undang-Undang Republik Indonesia Tentang Jalan, Republic of Indonesia, 2004, p. 29.

[3] P. Menteri and P. Umum, "No Title," 2010.

[4] AASHTO, "Policy on geometric design of highways and streets," American Association of State Highway and Transportation Officials. 2001.

[5] I. B. Potts, D. W. Harwood, and K. R. Richard, "Relationship of Lane Width to Safety on Urban and Suburban Arterials," Transp. Res. Rec. J. Transp. Res. Board, no. 2023, pp. 63-82, 2007.

[6] A. P. Akgüngör and O. Yildiz, "Sensitivity Analysis of an Accident Prediction Model by The Fractional Factorial Method," Accid. Anal. Prev., vol. 39, pp. 63-68, 2007.

[7] M. A. Hadi, J. Aruldhas, C. Lee-Fang, and J. A. Wattleworth, "Estimating Safety Effects of Cross-Section Design for Various Highway Types Using Negative Binomial Regression," Transp. Res. Rec. J. Transp. Res. Board, vol. 1500, pp. 169-177, 1995.

[8] F. Gross, "Case-Control Analysis In Highway Safety: Accounting for Sites With Multiple Crashes," Accid. Anal. Prev., vol. 61, pp. 87-96, 2013.

[9] D. Lord and J. A. Bonneson, "Development of Accident Modification Factors for Rural Frontage Road Segments in Texas," Transp. Res. Rec. J. Transp. Res. Board, 2007.

[10] J. Park and M. Abdel-aty, "Safety Performance of Combinations of Traffic and Roadway Cross-Sectional Design Elements at Straight and Curved Segments,"J. Transp. Eng. Part A, vol. 143, no. 6, 2017.

[11] O. Yanmaz-Tuzel and K. Ozbay, "A Comparative Full Bayesian Beforeand-After Analysis And Application to Urban Road Safety Countermeasures in New Jersey," Accid. Anal. Prev., vol. 42, no. 6, pp. 2099-2107, 2010.

[12] J. E. Hummer, W. Rasdorf, D. J. Findley, C. V Zegeer, and C. A. Sundstorm, "Curve Collisions: Road and Collision Characteristics and Countermeasures," J. Transp. Saf. Secur., vol. 2, no. 3, 2009.

[13] M. Banihashemi, "Effect of Horizontal Curves on Urban Arterial Crashes," Accid. Anal. Prev., vol. 95, pp. 20-26, 2016.

[14] D. J. Torbic, D. W. Harwood, D. K. Gilmore, R. Pfefer, T. R. Neuman, K. L. Slack, and K. K. Hardy, A Guide for Reducing Collisions on Horizontal Curves, 2004.

[15] M. S. Rune elvik, Truls Vaa, Alene Hoye, The hanbook of road safety measures, 2009.

[16] R. Elvik, "International Transferability of Accident Modification Functions for Horizontal Curves," Accid. Anal. Prev., vol. 59, pp. 487496, 2013.

[17] L. Brockebrough, R and J. Boedecker, K, Highway engineering handbook: building and rehabilitation the infrastructure, 2003.

[18] R. Fu, Y. Guo, W. Yuan, H. Feng, and Y. Ma, "The correlation between gradients of descending roads and accident rates," Saf. Sci., vol. 49, no. 3, pp. 416-423, 2011.

[19] Z. Hang and S. Teng, "Influence of Traffic Safety on Road Alignment," Am. Soc. Civ. Eng., pp. 1280-1285, 2012.

[20] P. Rautela and S. S. Pant, "Effect of Horizontal Curves on Urban Arterial Crashes," Disaster Prev. Manag., vol. 16, no. 3, pp. 334-344, 2007.

[21] Federal Highway of Administration [FHWA], Distress Identification Manual for the Long-Term Pavement Performance Program, Federal Highway Administration, Georgetown Pike McLean, 2014.

[22] J. Lee, B. Nam, and M. Abdel-aty, "Effects of Pavement Surface Conditions on Traffic Crash Severity," J. Transp. Eng., vol. 141, no. 10, 2015.

[23] M. G. Karlaftis and I. Golias, "Effects Of Road Geometry And Traffic Volumes on Rural Roadway Accident Rates," Accid. Anal. Prev., vol. 34, pp. 357-365, 2002. 
[24] P. C. Anastasopoulos and F. L. Mannering, "A Note on Modeling Vehicle Accident Frequencies with Random-Parameters Count Models," Accid. Anal. Prev., vol. 41, pp. 153-159, 2009.

[25] S. Labi, "Efficacies of Roadway Safety Improvements Across Functional Subclasses of Rural Two-Lane Highways," J. Safety Res., vol. 42, no. 4, pp. 231-239, 2011.

[26] Y. Li, C. Liu, and L. Ding, "Impact of pavement conditions on crash severity," Accid. Anal. Prev., vol. 59, pp. 399-406, 2013.

[27] C. Y. Chan, B. Huang, X. Yan, and S. Richards, "Investigating Effects of Asphalt Pavement Conditions on Traffic Accidents in Tennessee Based on The Pavement Management System (PMS)," J. Adv. Transp., vol. 44, no. 3, pp. 150-161, 2010.

[28] J. Gao, J. Zhang, and M. Luo, "Study on The Relationship Between Asset Condition and Safety ( Part 1 )," J. Highw. Transp. Res. Dev., vol. 8, no. 2, pp. 99-104, 2014.

[29] Panduan Teknis 2 Manajemen Hazard Sisi Jalan, Technical Guide 2: Road Side Hazard Management, Indonesia, 2012.

[30] J. Lee and F. Mannering, "Impact of Roadside Features on The Frequency and Severity of Run-Off-Roadway Accidents: An Empirical Analysis," Accid. Anal. Prev., vol. 34, pp. 149-161, 2002.

[31] K. K. Dixon, M. Liebler, H. Zhu, M. P. Hunter, and B. Mattox, Safe and aesthetic design of urban roadside treatments, 2008.

[32] J. M. Pardillo-Mayora, C. A. Domínguez-Lira, and R. Jurado-Pina, "Empirical Calibration of a Roadside Hazardousness Index for Spanish Two-Lane Rural Roads," Accid. Anal. Prev., vol. 42, pp. 2018-2023, 2010.

[33] C. Roque, F. Moura, and J. L. Cardoso, "Detecting unforgiving roadside contributors through the severity analysis of ran-off-road crashes," Accid. Anal. Prev., vol. 80, pp. 262-273, 2015.

[34] M. Budzynski, K. Jamroz, L. Jelinski, and M. Antoniuk, "Why are Trees Still Such a Major Hazard to Drivers in Poland ?," in Transportation Research Procedia, vol. 14, pp. 4150-4159, 2016.

[35] D. S. Turner and E. R. Mansfield, "Urban Trees and Roadside Safety," J. Transp. Eng., vol. 116, no. 1, pp. 90-104, 1990.

[36] M. H. Ray, L. A. Troxel, and J. F. Carney, "Characteristics of FixedRoadside-Object Side-Impact Accidents," J. Transp. Eng., vol. 117, no. 3, pp. 281-297, 1991.

[37] H. Zhou and R. D. Layton, "Development of Prototype Expert System for Rodside Safety," J. Transp. Eng., vol. 117, no. 4, pp. 435-443, 1991.

[38] P. DeLeur, W. Abdelwahab, and F. Navin, "Evaluating Roadside Hazards Using Computer-Simulation Model," J. Transp. Eng., vol. 120, no. 2, pp. 229-245, 1994.

[39] B. J. Lee, T. Y. Jang, W. Wang, and M. Namgung, "Design Criteria for an Urban Sidewalk Landscape Considering Emotional Perception," $J$. Urban Plan. Dev., vol. 135, no. 4, pp. 133-140, 2009.

[40] J. Evans-cowley, "Sidewalk Planning and Policies in Small Cities," $J$. Urban Plan. Dev., vol. 132, no. 2, pp. 71-75, 2006.

[41] V. Wicramasinghe and S. Dissanayake, "Evaluation of Pedestrians' Sidewalk Behavior in Developing Countries," Transportation Research Procedia, vol. 25, pp. 4068-4078, 2017.

[42] E. Dumbaugh and W. Li, "Designing for the Safety of Pedestrians, Cyclists, and Motorists in Urban Environments Eric," J. Am. Plan. Assoc., vol. 77, no. 1, pp. 69-88, 2011.

[43] A. Osama and T. Sayed, "Evaluating The Impact of Connectivity, Continuity, and Topography of Sidewalk Network on Pedestrian Safety," Accid. Anal. Prev., vol. 107, pp. 117-125, 2017.

[44] M. V. Corazza, P. Di Mascio, and L. Moretti, "Managing Sidewalk Pavement Maintenance : A Case Study to Increase Pedestrian Safety," $J$. Traffic Transp. Eng. (English Ed., vol. 3, no. 3, pp. 203-214, 2016.

[45] N. Sousa, J. Coutinho-rodrigues, and E. Natividade-Jesus, "Sidewalk Infrastructure Assessment Using a Multicriteria Methodology for Maintenance Planning," J. Infrastruct. Syst., vol. 23, no. 4, pp. 1-9, 2017.

[46] X. Yang, H. Xu, X. Gao, and K. Long, "Study of Setting Conditions of Bus Bay Stop of Single Driveway," J. Highw. Transp. Res. Dev., vol. 6, no. 1 , pp. $66-71,2012$

[47] D. Chimba, T. Sando, and V. Kwigizile, "Effect of bus size and operation to crash occurrences," Accid. Anal. Prev., vol. 42, no. 6, pp. 2063-2067, 2010.
[48] L. T. Truong and S. V. C. Somenahalli, "Using GIS to Identify Pedestrian- Vehicle Crash Hot Spots and Unsafe Bus Stops," J. Public Transp., vol. 14, no. 1, pp. 99-114, 2011.

[49] F. Nakamura, "A Study on Improvement of Bus-Bay Design," J. East. Asia Soc. Transp. Stud., vol. 6, pp. 449-456, 2005.

[50] T. A. Rosinbum, W. Grote, and D. F. Jickling, "Bus Bay Street-Related Improvements in Phoenix and Tucson," Inst. Transp. Eng., vol. 61, no. 8, pp. 19-22, 1991

[51] R. Z. Koshy and V. T. Arasan, "Influence of Bus Stops on Flow Characteristics of Mixed Traffic," J. Transp. Eng., vol. 131, no. 8, pp. 640-643, 2005.

[52] "No Title," 2014

[53] P. Konstantopoulos, P. Chapman, and D. Crundall, "Driver's Visual Attention as a Function of Driving Experience and Visibility. Using a Driving Simulator to Explore Drivers' Eye movements in Day, Night and Rain Driving," Accid. Anal. Prev., vol. 42, pp. 827-834, 2010.

[54] T. Horberry, J. Anderson, and M. A. Regan, "The Possible Safety Benefits of Enhanced Road Markings: A Driving Simulator Evaluation," Transp. Res. Part F, vol. 9, pp. 77-87, 2006.

[55] D. de-Waard, F. J. J. M. Steyvers, and K. A. Brookhuis, "How Much Visual Road Information is Needed to Drive Safely and Comfortably?," Saf. Sci., vol. 42, no. 7, pp. 1-17, 2004.

[56] K. Diamandouros and M. Gatscha, "Rainvision: The Impact of Road Markings on Driver Behaviour-Wet Night Visibility," Transportation Research Procedia, vol. 14, pp. 4344-4353, 2016.

[57] S. Daniels, J. Vanrie, A. Dreesen, and T. Brijs, "Additional Road Markings as an Indication Of Speed Limits: Results of a Field Experiment and a Driving Simulator Study," Accid. Anal. Prev., vol. 42, pp. 953-960, 2010.

[58] C. Coutton-Jean, D. R. Mestre, C. Goulon, and R. J. Bootsma, "The Role of Edge Lines in Curve Driving," Transp. Res. Part F Psychol. Behav., vol. 12, pp. 483-493, 2009.

[59] Republik Indonesia, Undang-undang Republik Indonesia Nomor 22 Tahun 2009 Tentang Lalu Lintas dan Angkutan Jalan. Republik Indonesia, pp. 1-60, 2009.

[60] G. B. Kolisetty, T. Iryo, Y. Asakura, and K. Kuroda, "Effect of Variable Message Signs on Driver Speed Behavior on a Section of Expressway under Adverse Fog Conditions - A Driving Simulator Approach,” $J$. Adv. Transp., vol. 40, no. 1, pp. 47-74, 2005.

[61] W. Guan, X. Zhao, Y. Qin, and J. Rong, "An Explanation of How the Placement of Traffic Signs Affects Drivers' Deceleration on Curves," Saf. Sci., vol. 68, pp. 243-249, 2014.

[62] X. Zhao, Y. Wu, J. Rong, and J. Ma, "The Effect of Chevron Alignment Signs on Driver Performance on Horizontal Curves With Different Roadway Geometries," Accid. Anal. Prev., vol. 75, pp. 226-235, 2015.

[63] S. G. Charlton, "The Role of Attention In Horizontal Curves: A Comparison of Advance Warning, Delineation , and Road Marking Treatments," Accid. Anal. Prev., vol. 39, pp. 873-885, 2007.

[64] S. Plainis and I. J. Murray, "Reaction Times as an Index of Visual Conspicuity When Driving at Night," Ophthalmic Physiol. Opt., vol. 22, pp. 409-415, 2002.

[65] A. F. Williams, "Teenage Drivers : Patterns of Risk," J. Safety Res., vol. 34 , pp. 5-15, 2003

[66] P. O. Wanvik, "Effects of Road Lighting: An Analysis Based on Dutch Accident Statistics 1987 - 2006," Accid. Anal. Prev., vol. 41, pp. 123128,2009

[67] M. Jackett and W. Frith, "Quantifying the Impact of Road Lighting on Road Safety -A New Zealand Study," IATSSR, vol. 36, pp. 139-145, 2013.

[68] E. T. Donnell, R. J. Porter, and V. N. Shankar, "A Framework for Estimating the Safety Effects of Roadway Lighting at Intersections," Saf. Sci., vol. 48, pp. 1436-1444, 2010.

[69] A. J. Anarkooli and M. H. Hosseinlou, "Analysis of the Injury Severity of Crashes by Considering Different Lighting Conditions on Two-Lane Rural Roads," J. Safety Res., pp. 57-65, 2016.

[70] K. Jamroz, M. Budzynski, W. Kustra, L. Michalski, and S. Gaca, "Tools for Road Infrastructure Safety Management - Polish Experiences," in Transportation Research Procedia, 2014, vol. 3, pp. 730-739.

[71] W. Kustra, K. Jamroz, and M. Budzynski, "Safety PL - A Support Tool for Road Safety Impact Assessment," in Transportation Research Procedia, 2016, vol. 14, pp. 3456-3465. 
[72] L. Persia, D. S. Usami, F. De Simone, V. F. D. La Beaumelle, G. Yannis, A. Laiou, S. Han, K. Machata, L. Pennisi, P. Marchesini, and M. Salathè, "Management of Road Infrastructure Safety," Transportation Research Procedia, vol. 14, pp. 3436-3445, 2016.

[73] A. Bener, F. M. Abu-Zidan, A. K. Bensiali, A. A. Al-Mulla, and K. S. Jadaan, "Strategy to Improve Road Safety in Developing Countries," Saudi Med J., vol. 24, no. 6, pp. 603-608, 2003.

[74] T. Bliss and J. Breen, "Meeting the management challenges of the Decade of Action for Road Safety," IATSS Res., vol. 35, no. 2, pp. 4855,2012 